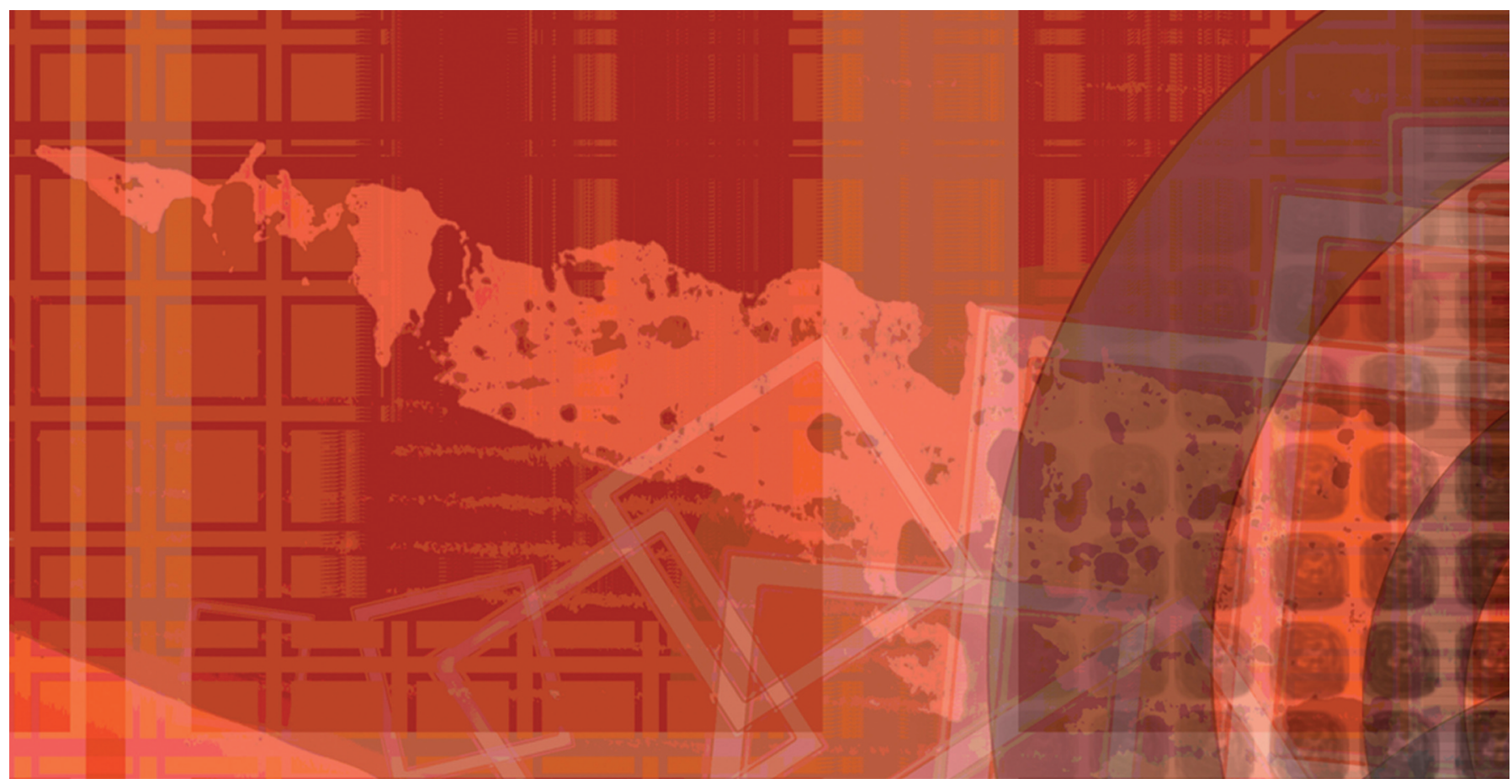

\title{
A Conversation with Leslie Pendrill, SP Technical Research Institute of Sweden and EURAMET
}

\section{Introduction}

Prof. Leslie Pendrill has been the Head of Research of the Measurement Division at the SP Technical Research Institute of Sweden since 1985. His research work is concerned with fundamental metrology, in particular optoelectronic, laser, length, and mass measurements, while his applied metrology activities include optimized measurement uncertainty studies and the measurement of perception. He is actively involved in several international metrology activities, holding leading roles such as currently the 2009-2012 Chair of the European Association of National Metrology Institutes (EURAMET) and earlier as Chair (2006-2008) of the International Union of Pure and Applied Physics (IUPAP) Commission on Symbols, Units, Nomenclature, Atomic Masses and Fundamental Constants (SUNAMCO). He has just become a member of the NCSLI Board as EURAMET Representative.

Q. NCSLI is very pleased to interview you for its metrology journal measure. You have been a long time supporter of NCSLI and have attended many of the annual NCSLI Workshop \& Symposiums, as well as the Measurement Science Conference (MSC), since the mid 1980's. Since you have had leading roles in international, European and Swedish national metrology for almost 25 years, you have seen steady growth in both European

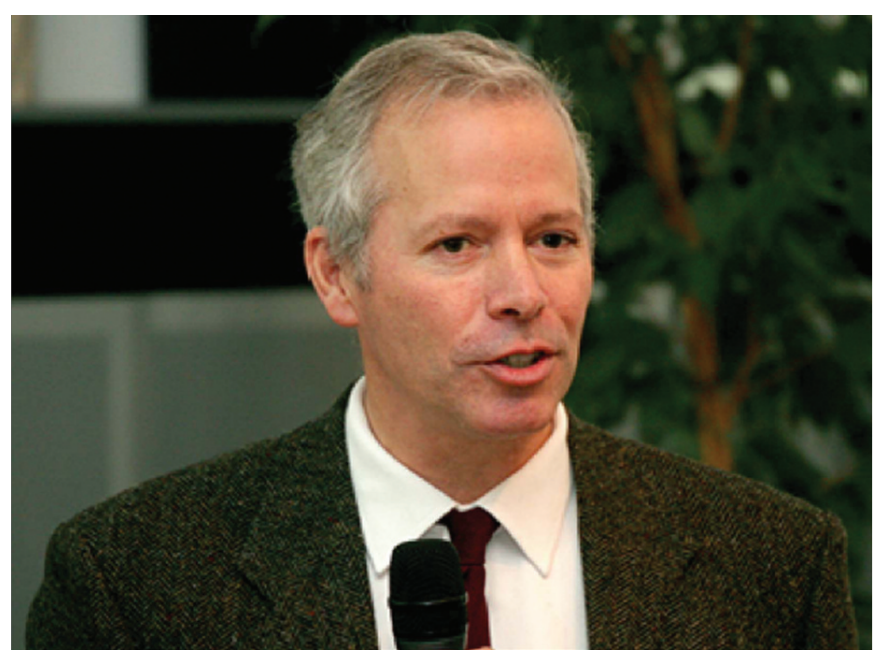

Leslie Pendrill, Head of Research at the Measurement Division, SP Sweden and EURAMET Chair.

Metrology and Swedish National Metrology. What are your current views about the interplay between national, European and international strategy in quality-assured measurement in supporting manufacturing and technology industries and in meeting society's challenges at large? 
A. Business and society are making increasing demands on measurements in terms of complexity, combined with higher accuracy, often in response to the global "Grand Challenges" of today's society. The support that quality-assured measurement ('metrology') provides to sustainability and innovation is wellknown and has a long history. Metrological traceability means that the results of measurements can be compared in an objective way, both reproducibly and even amongst different measurement quantities. That in turns ensures that products and processes in a wide range of sectors can more efficiently work together. In addition, communication is improved so that products can be traded, ensuring their safety, and that they are kept within specifications. Measurement uncertainty for its part gives an indication of measurement quality, which is essential in assessing the real value and impact of a measurement result.

Metrology continues to support traditional sectors, including global trade, which indeed stimulated the first international convention, namely the Meter Convention of 1875 . During the $20^{\text {th }}$ Century, metrology increasingly supported the manufacturing and process industries. Now, a decade into the $21^{\text {st }}$ Century, quality-assured measurement is additionally engaged with the 'emerging' sectors, such as security, healthcare and climate change. To have close and secure access to accurate measurements that are traceable to the International System of Units (SI) (meter, kilogram, second, etc.) is a prerequisite for a modern industrial society, whatever sector is considered.

Thus, metrology is closely linked to industry and society. With a small home market (8 million inhabitants in a land area similar to California), Sweden has always been a country with an international perspective, be it in diplomacy or in major, multinational enterprises. The process industries, including forestry, paper and mining, are relatively strong in Sweden and have major international exports. Manufacturing industries in sectors such as the automotive, pharmaceutical, and information and communication technologies (ICT), include well-known brands such as Volvo, Saab, Ericsson, AstraZeneca, etc., with markets far larger than the modest domestic demands. Swedish enterprises in the retail business, such as IKEA, TetraPak and H\&M Hennes \& Mauritz, are globally renowned. Energy and the environment are always high on the Swedish agenda. Amongst countries with research-intensive industries, Sweden has proportionally a rather high number of companies among the top rankings.

Sweden can appear to be a bit remote, since it is located on the Northern periphery of the Continent, and perhaps not the most Europhile of the European Union's countries; it joined the $\mathrm{EU}$ as late as 1995 and is not yet in the Eurozone. Nevertheless, in the last quarter century, Sweden has become successively more an integrated part of Europe, most recently as host for the Presidency of the EU Council of Ministers in the $2^{\text {nd }}$ half of 2009. Of course, Europe is a major export market for Swedish industry, but not exclusively since North America, Asia and the developing world are at least as important. The Swedish academic sector for its part can seem somewhat ambivalent to

\footnotetext{
${ }^{1}$ Chairman of Board of the Swedish Research Council, www.sulf.se/templates/CopyrightPage.aspx?id=10430 (in Swedish).
}

European research integration, stating recently for example that it is "more important what Member Countries do at home, while EU's research program constitutes only about $5 \%$ of our national budgets." 1

In their role as national metrology institutes (NMIs), organizations such as SP Sweden emphasize that they are neither industries nor academies, but something in between. Instead these institutes have a unique, intermediary position in the innovation value chain linking academic research and ordinary, commercially provided measurement services. The institute's goals are based on and declared in terms of a proven competency balanced against explicitly expressed needs for quality-assured measurement. From the picture I have given above of Swedish industry, one can draw parallels between industrial allegiances with national and international stakeholders to the corresponding allegiances in metrology. Swedish national metrology (which is mainly concentrated in SP Sweden) has a clear role in support of local industry and society as an essential, albeit 'invisible,' part of the country's technological infrastructure. But increasingly, the ever growing demands for metrological resources in response to global challenges are best met with transnational cooperation.

At the moment, there is much discussion and debate in Europe about finding a balance between national and European research efforts, with concepts such as 'smart specialization' in the European Research Area and in encouraging researcher mobility. Swedish national metrology aims at creating a local critical mass in a small country so that it can attempt to create several European centers of excellence in metrology in the 'Far North.'

Q. What are your major goals for the Measurement Division during the next $5-10$ years?

A. In formulating goals for national metrology, one can usefully plan in terms of technological foresight, including roadmaps extending perhaps 15 years into the future. However responsive we are in setting goals in terms of the needs of industry and society, institutes like SP, with their unique, intermediary role discussed above, need nevertheless to look beyond immediate needs and plan long-term. The immediate requirements for quality-assured measurement are best provided by the commercial sector. Almost all countries support a national metrology program with government funds and one often talks of 'market failure' in national metrology. The 'competency' referred to here means the 'best' metrology can offer - otherwise someone else can just as well provide it, and the 'needs' referred to here means the long-term requirements of society and industry. This is not say that national metrology institutes are 'aloof ivory towers' as some might see us, since we are in constant, daily contact with society and industry. Institutes disseminate traceability and metrological know-how to secondary calibration laboratories, that do the 'real, frontline' job.

In the coming years, our goals will be set in three ways: (i) meeting the Grand Challenges mentioned already; (ii) measuring 'domestic' measurement needs; and (iii) last but not least,

Continued on page 24 
increasing our outreach and metrological knowledge exchange in its broadest meaning.

Speaking of metrology outreach, I've been inspired by activities that the NCSLI is doing so well in this area and was proud to share the NCSLI best invited paper award with Georgia Harris a couple of years back where we compared and contrasted European and North American approaches to metrology knowledge exchange. [1]

Sweden is well-known globally for its long history of support for international development through programs such as the Swedish International Development Cooperation Agency (SIDA). And as part of this, SP Sweden is known as a small, but reliable, actor in quality infrastructure programs in the developing world, be it in Africa, Central America or in the neighboring regions of Europe. I personally enjoy teaching, at the university level, as well as in industry, and readers are welcome to try our on-line (free) Internet based handbook "Application of Statistical Methods in Measurement \& Testing” at http://metrology.wordpress.com.

Another important component in metrological outreach is making visible the role of metrology in the wider context of conformity assessment of products and services of all kinds. National metrology is a key player in providing proactive policy advice to regulatory bodies where new technology and new metrology need to be developed in order to meet emerging challenges, such as safe nanoproduction.

One main, determining factor in deciding the major goals for Swedish metrology in the next 5 to 10 years is the emergence of a major European metrology research program, the $400 \mathrm{M} €$ European Metrology Research Programme (EMRP) [2] where there might be a chance to create European centers of metrological excellence in Sweden.

Q. SP Sweden is a very active and important national metrology institute in Europe. It has collaborated with the European Association of National Metrology Institutes (EURAMET), and sup-

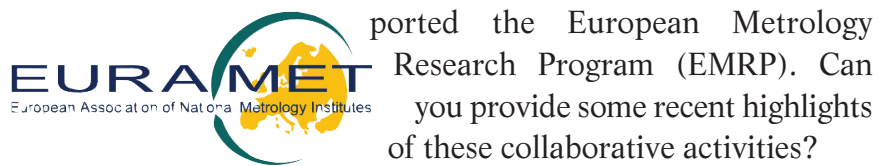
A. What is exciting just now in European metrology cooperation is that members of EURAMET are not merely adding together their national metrology programs but are indeed, at least partially, integrating resources into a truly regional program. Recent developments in European metrology - the dramatic growth of EURAMET to over 100 member organizations in 34 countries and the start of a $400 \mathrm{M} €$ European Metrology Research Program (EMRP) - mean that national metrology programming increasingly includes European, as well as national, aspects as one of the most advanced examples of the flagship European Research Area. We estimate that as much as $25 \%$ of national metrology research budgets will now be truly European. You can read more about the EMRP in Andy Henson's recent NCSLI Measure article. [3]

It is important to realize that this development of European metrology is not dominated by a few, large European countries, and by far the majority of EURAMET members by number are countries of comparable size to Sweden. As EURAMET Chair during the next three years, I am responsible for leading activities that EURAMET coordinates and for encouraging cooperation throughout Europe. [4] Of course, there are still some purely national concerns and, from a Swedish point of view, it is important that Sweden is given a chance to be an active part of the European metrology, so that:

- Swedish companies should not be at a competitive disadvantage.

- Swedish skills will be made available to Europe.

But as Chair, I don't solely represent Sweden: Making sure the voices of all European NMIs are heard, irrespective of whether they are from large or small countries, I see as one of the main hallmarks of my Chairmanship. And this is no mean challenge, bearing in mind the enormous differences, by almost a factor 200, between the largest and smallest EURAMET members.

I suppose I'm a Europhile, but this does not mean that I'm in favor of a fully centralized European Bureau of Standards! There has been much talk about eliminating unnecessary redundancy amongst the different NMIs and letting 'market forces' find the optimum sharing of metrological resources and services in Europe. As a counterweight, in my Chairman's editorial in the latest EURAMET Newsletter [5], I remind readers of the old adage about the composer Schubert who might have finished his "Unfinished Symphony" had he used modern quality assurance methods - you know, all those unnecessary 'demi-semiquavers' so typical of the national metrologist! I believe metrology is a classic area where the market 'fails.' Instead, organisations such as EURAMET can be described as composing a Symphony of Excellence, to echo a recent issue of the EU Commission's magazine "research*eu" [no. 61, July 2009], but with many instruments in each part of the orchestra.

EURAMET and the EMRP are enabling even the smaller countries to aim at becoming 'Centers of Excellence.'

Metrology in Energy has been the topic for the first announcement in 2009 of the EURAMET EMRP Article 169 Research Program, and the preliminary outcome of proposal evaluation indicates considerable support to Swedish researchers. Amongst the projects proposed by Sweden, SP Sweden aims to coordinate a project on Metrology for HVDC, i.e., high-voltage direct current electrical energy transport systems as part of the establishment in Sweden of a European center of excellence in this field. SP Sweden already has internationally unique measurement skills in the field, and, at the same time, unique efforts in the development of this kind of novel energy system are at present being made in Sweden, including the so-called South-West link which is using some of the most modern dc high-voltage technology.

During this Spring, EURAMET is also announcing EMRP Calls for Metrology in Industry and the Environment, and SP Sweden aims to be proactive even in these areas. Everyone is welcome to suggest Topics for Research - see www.euramet.org!

Q. The accreditation system in Sweden is operated by the Swedish Board for Accreditation and Conformity Assessment, SWEDAC. What is SP Sweden's role supporting the accreditation of calibration and testing laboratories in Sweden?

A. I've been in metrology long enough to remember the time 


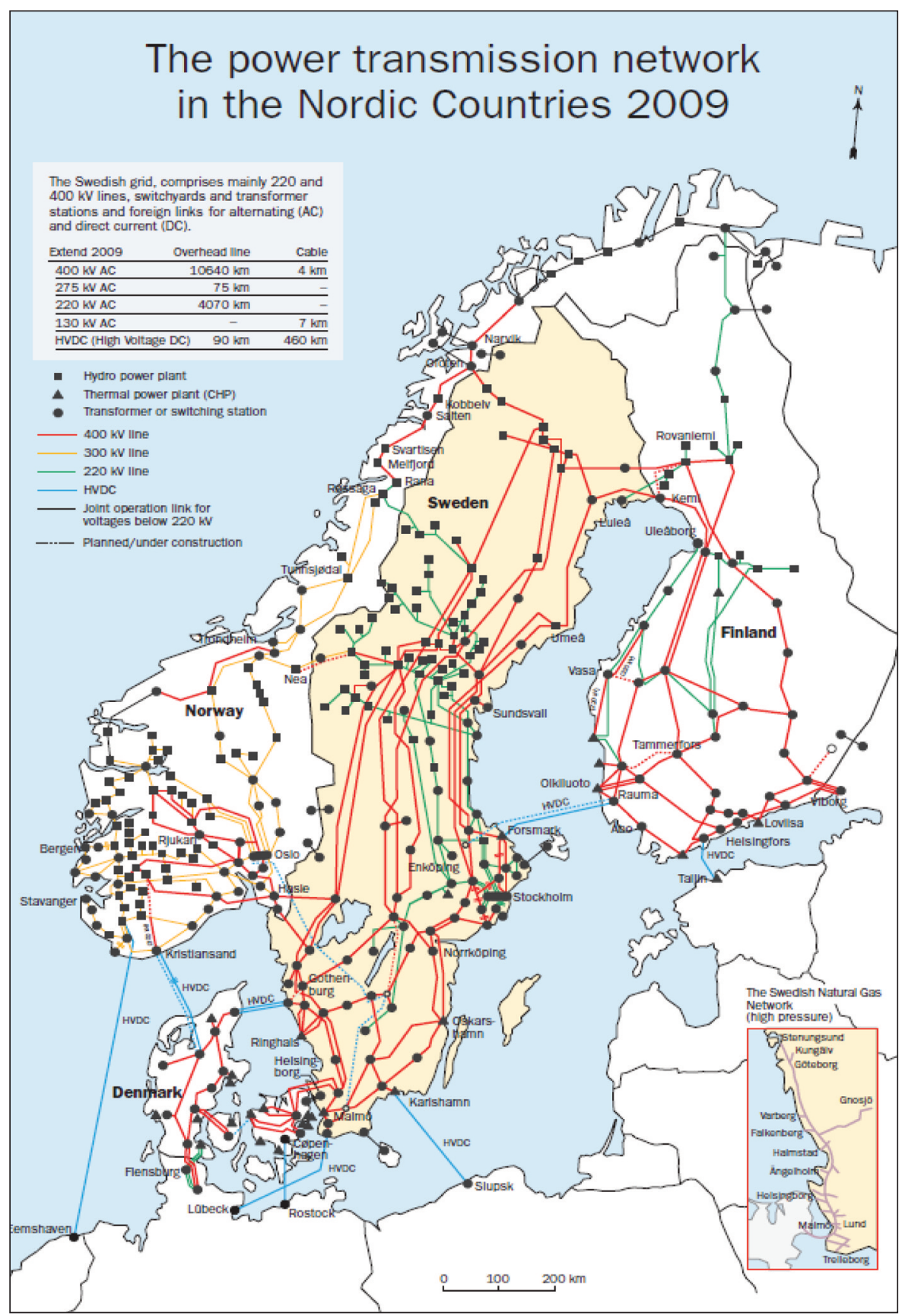

Swedish Power Network [Svenska kraftnät, www.svk.se/Start/English/PressInformation/Annual-report/]

before accreditation. Indeed, many accreditation bodies such as SWEDAC were 'spawned' from national metrology institutes. So relations between NMIs and accreditation bodies over the years might be described as typical of siblings! SP Sweden is happy to provide many of the technical experts used in the assessment of Swedish accredited calibration laboratories.

I promote more generally the role of quality-assured measurement in Conformity Assessment: NMIs provide invaluable support to Conformity Assessment
Q. SP Sweden has concentrated efforts on developing new mathematical methods that support measurement technology. This work has ranged from developing algorithms for combining measurements from different clocks in order to obtain better time and uncertainty estimates to developing methodologies to balance the cost of a measurement against the cost of the consequences of wrong decisions, all as a function of measurement uncertainty. Can you provide a status report on these mathematical methods?

A. SP has developed algorithms for combining measurements from different clocks in order to obtain better time estimates and to provide an associated uncertainty estimate. The algorithms are based on several interacting Kalman filters, giving at any time the best possible time estimate together with a measure of its associated quality. The technique is used today to maintain the Swedish national time scale UTC(SP) which is a national realization of the Coordinated Universal Time (UTC).

In addition, we have recently developed a new methodology that combines economic factors with measurement uncertainty. The cost of measurement is balanced against the cost of the consequences of wrong decisions, as a function of measurement uncertainty. This work grew out of my realizing, after given courses of twenty years for industrial and laboratory metrologists in how to evaluate measurement uncertainty, that there always remained the question: What is the right 'fit-for-purpose' level of measurement uncertainty? No measurement is made purely for its own sake. And we often get the question: What is the impact of your measurements? There is no point in making highly accurate measurements or spending a lot of time and effort analyzing different components of uncertainty, if the job at hand doesn't require such sophistication. On the other hand, a sloppy measurement with large uncertainties will cost much more in terms of bad decisions than any savings on measurement.

Luckily, I found that a group of chemists and statisticians in London UK

Continued on page 26 


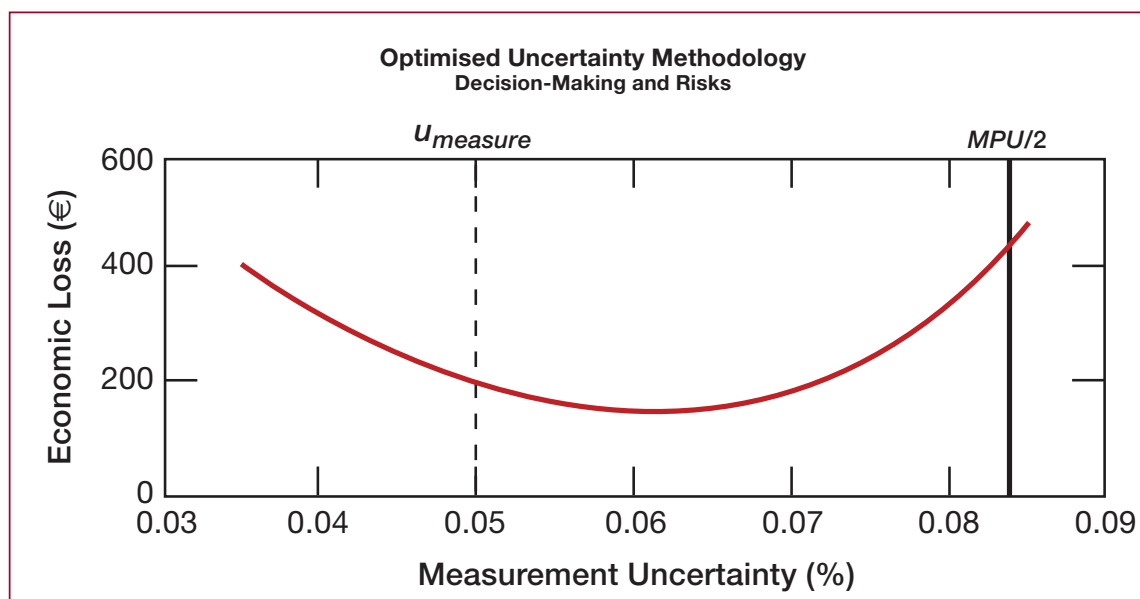

$\leftarrow$ Too much testing

Optimizing measurement uncertainties, $u_{\text {measure }}$, by balancing costs of testing against consequence costs in conformity-assessment decisions (MPU, Maximum Permissible Uncertainty, is a target uncertainty). [6]

had in the mid-90's developed a so-called 'optimized uncertainty' methodology which they applied to analytical measurements. I took up their approach ten years later and extended it to a whole range of measurements as a type of prototype study on the role of qualityassured measurements in conformity assessment of all kinds of product.

One basic example is an analysis of fitfor-purpose measurement uncertainty when testing the contents of a wide range of consumer products, such as pre-packaged cheese, coffee powder, shampoo, etc. Here the approach works well both when testing by variable as well as in classical statistical acceptance sampling by attribute (that is, 'go/no-go' decisions). I have added a third dimension to the optimized uncertainty methodology by including a new kind of tool: the cost characteristic power curve. Many examples have been analyzed in legal metrology, arguably the first formalized approach to general conformity assessment, where challenges such as 'fit-forpurpose' testing of measuring instruments for metering energy or environmental emissions have been successfully dealt with. [6]

Q. SP Sweden, as other NMIs, is heavily involved in supporting the Key Comparisons as part of the Bureau International des Poids et Mesures (BIPM) International Committee for Weights and Measures Mutual Recognition Arrangement
(CIPM MRA). Can you summarize your views of the status of the calibration services of SP Sweden that are currently listed in Appendix C of the CIPM MRA and SP Sweden's future plans for the recognition of additional calibration services under the MRA?

A. Since SP Sweden bases its national metrology on a balance of needs and competence, our calibration services should in principle reflect these. The Calibration and Measurement Capabilities (CMC) declared in the CIPM database, together with the results of key comparisons, are, as you know, under constant review by the regional metrology organizations. There is ideally a chain of activities linking research to the end-users, in which new measurement know-how is implemented in improved calibration and measurement capabilities. Part of my own research recently has in fact been aimed at going beyond just the numbers and focusing on a modeling of 'fit-forpurpose' Calibration \& Measurement Capabilities, using the optimized uncertainty methodology described above to balance the costs of maintaining $\mathrm{CMCs}$ against the needs of testing, and has recently been published, together with Slovenian colleagues. [7] So hopefully the Swedish CMCs should in principle not only be validated but also be 'fit-forpurpose'!

Of increasing concern to me is that it is at least as equally important to promote Key Comparisons - proficiency testing, if you will - at the secondary calibration laboratory level, so that industry's own laboratories can declare reliable and proven Calibration and Measurement Capabilities for their customers.

Q. SP Sweden is in the process of developing new metrology capabilities in a variety of non-traditional areas, such as nanotechnology, surface analysis, inorganic and organic chemical analysis, and biological analysis. Can you highlight some of Sweden's needs in these areas and projects that will address them?

A. As is well known, nanotechnology is promising a spectacular innovative growth of a wide range of novel products. Nanometrology, which is defined as the measurement and characterisation of structures with at least one dimension in the range 1 to $100 \mathrm{~nm}$, can provide an essential infrastructure to support sustainable growth in nanoproducts. Quality-assured measurement, i.e., metrological traceability and measurement uncertainty, ensures quality-assured products since it is a key step in assessing product quality characteristic compliance with specifications, e.g., in a regulatory context. This is particularly important where product characteristics at the nanoscale are of concern, for example, potential health risks or other performance requirements.

Sweden is relatively strong in academic nanoscience, but, like other countries, seems to be less successful in transferring and exploiting nanotechnology into innovative products.

SP Sweden is part of a European project, called CO-NANOMET [8] Coordination of Nanometrology in Europe, which is formulating a European strategy and action plan in support of improved transfer and exploitation of nanotechnology into innovative products through better quality-assured measurement. SP Sweden has two main roles in the CONANOMET project: (1) leading a study of industrial exploitation of nanometrology and (2) the creation of a European Nanometrology Action Group in Nanobiotechnology defined in this instance as the application of nanosciences, nanoscale phenomena or nanotechnologies in bio- and life-science and technology, initially focused on the health care sector, 


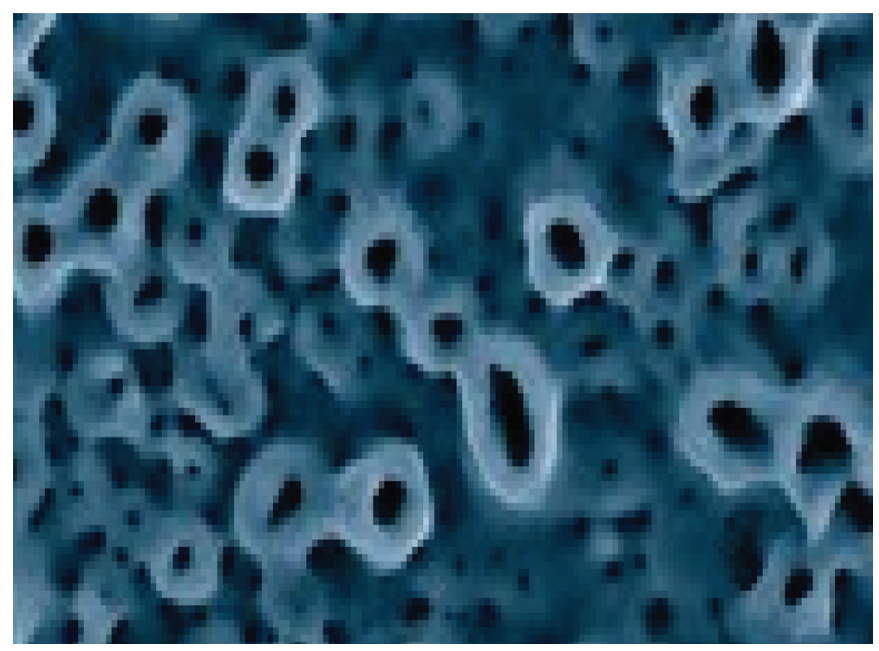

Scanning electron microscopy image of nanostructures of a titanium human implant that will influence the tissue response to the material.

but the food sector is also addressed to some extent. This work is extending nanometrology beyond dimensional metrology to also include quality-assured measurement of the chemical and biological properties of nanosystems.

Q. Are there some other new or exciting metrology or measurement activities at SP Sweden that you would like to communicate to the members of NCSLI?

A. Traditional physiological metrology needs to be complemented in several ways, as it is becoming increasingly recognised that psychophysical, mental and behavioral processes are known to affect significantly the human response to various stimuli, take pain as an example. Quality-assured measurement in measurement systems where human being plays a key role is relatively underdeveloped, despite great potential for innovation and particularly in applications where humans are an important component of critical systems, where for instance health and safety are at stake. [10] As part of the European 'Measuring the Impossible' Network, MINET, which promotes new research activities in measurement dependent on human perception and/or interpretation, my colleagues and I at SP Sweden have

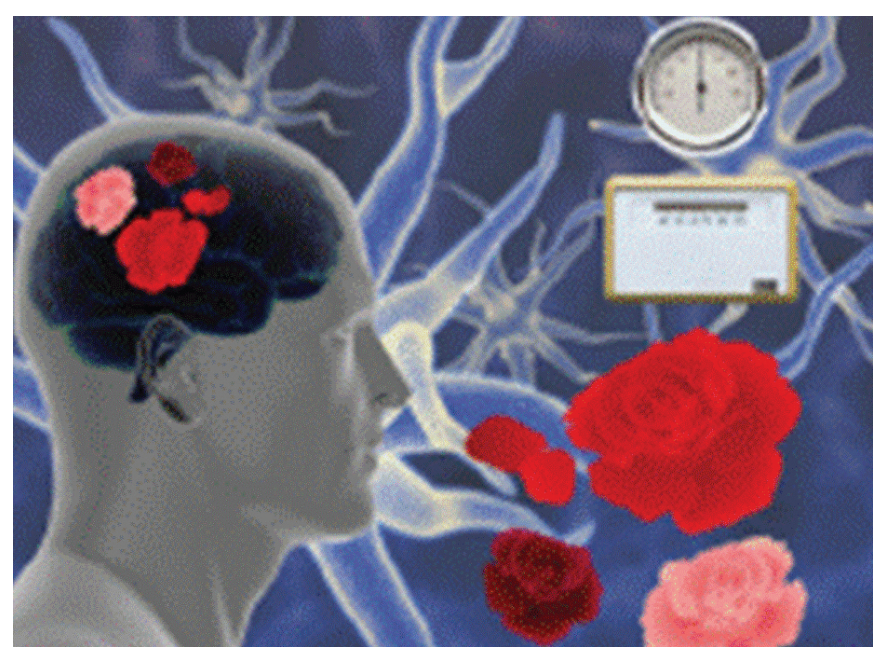

'Measuring the Impossible' Network (MINET). [9] led a series of think tanks and Internet-based repositories in metrology (quality-assured measurement) in the last three years. An example is an interdisciplinary glossary of concepts and terminology in Perceptive Metrology developed by this consortium of physicists, metrologists, medical scientists, neurologists, and scientists from psychology and sociology. [11]

\section{References}

[1] G. Harris and L.R. Pendrill, "Comparing and Contrasting Studies of Metrology Education and Training in Europe and North America,” NCSLI Measure, vol. 3, no. 2, pp. 38-45, 2008.

[2] EMRP 2009, "Decision No 912/2009/EC of the European Parliament and of the Council of 16 September 2009 on the participation by the Community in a European metrology research and development programme undertaken by several Member States," Official Journal of the European Union, L 257, vol. 52, pp. 12-25, 30/09/2009. (See http://eur-lex.europa.eu/ LexUriServ/LexUriServ.do?uri=OJ:L:2009:257:0012:0025:EN:PDF)

[3] Andy Henson, Michael Kühne and Luc Erard, "The European Metrology Research Programme in Action," NCSLI Measure, vol. 4, no. 4, pp. 26-33, 2009].

[4] L.R. Pendrill, "EURAMET: European Association of National Metrology Institutes," NCSLI Measure, vol. 4, no. 4, pp. 40-44, 2009.

[5] EURAMET Newsletter, Issue II, November 2009. See www.euramet.org/index.php?id=euramet-newsletter

[6] L.R. Pendrill, "Optimised Measurement Uncertainty and Decision-Making in Conformity Assessment," NCSLI Measure, vol. 2, no. 2, pp. 76-86, 2007.

[7] G. Beges, J. Drnovsek and L.R. Pendrill, "Optimising calibration and measurement capabilities in terms of economics in conformity assessment," Accred. Qual. Assur., 2009. DOI http://dx.doi.org/10.1007/s00769-009-0599-3.

[8] CO-NANOMET 2009 Coordination of nanometrology in Europe. See www.co-nanomet.eu/

[9] "MINET 2007-2010 Measuring the Impossible: Network," NEST Pathfinder project Contract No. 043297, 2010. See http://minet.wordpress.com

[10] L.R. Pendrill et al., "Measurement with Persons: A European Network”, NCSLI Measure, in press.

[11] MINET Glossary, 2009.

See http://minet3repository.wordpress.com/ measurement-domains/measurement-concepts-terminology/ minet-glossary-of-perceptive-metrology/

Prof. Leslie Pendrill

EURAMET Chair \& Delegate for Sweden

Head of Research, Measurement Technology

SP Technical Research Institute of Sweden

PO Box 857

SE-501 15 Borås

Sweden

Email:leslie.pendrill@sp.se 